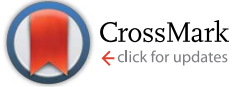

Cite this: J. Mater. Chem. A, 2014, 2 , 17649

Received 30th June 2014

Accepted 13th August 2014

DOI: $10.1039 / \mathrm{c} 4 \mathrm{ta} 03327 \mathrm{~b}$

www.rsc.org/MaterialsA

\section{Micro- and mesoporous carbide-derived carbon prepared by a sacrificial template method in high performance lithium sulfur battery cathodes $\uparrow$}

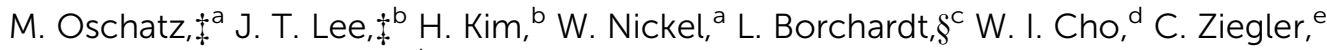 \\ S. Kaskel ${ }^{\star a}$ and G. Yushin*b
}

Polymer-based carbide-derived carbons (CDCs) with combined micro- and mesopores are prepared by an advantageous sacrificial templating approach using poly(methylmethacrylate) (PMMA) spheres as the pore forming material. Resulting CDCs reveal uniform pore size and pore shape with a specific surface area of $2434 \mathrm{~m}^{2} \mathrm{~g}^{-1}$ and a total pore volume as high as $2.64 \mathrm{~cm}^{3} \mathrm{~g}^{-1}$. The bimodal CDC material is a highly attractive host structure for the active material in lithium-sulfur ( $\mathrm{Li}-\mathrm{S}$ ) battery cathodes. It facilitates the utilization of high molarity electrolytes and therefore the cells exhibit good rate performance and stability. The cathodes in the $5 \mathrm{M}$ lithium bis(trifluoromethanesulfonyl)imide (LiTFSI) electrolyte show the highest discharge capacities (up to $1404 \mathrm{~mA} \mathrm{~h} \mathrm{~g}^{-1}$ ) and capacity retention (72\% after 50 cycles at C/5). The unique network structure of the carbon host enables uniform distribution of sulfur through the conductive media and at the same time it facilitates rapid access for the electrolyte to the active material.

\section{Introduction}

Porous carbon materials with large specific surface area, welldefined pore size, as well as high chemical and thermal stabilities stand out due to their large number of potential applications such as gas adsorption, ${ }^{1-3}$ catalysis, ${ }^{4,5}$ water treatment, ${ }^{6}$ and electrochemical energy storage..$^{7-9}$ Especially the needs for hierarchically structured micro- and mesoporous carbon materials are increasing because they can take benefits from both large specific surface area (micropores; $<2 \mathrm{~nm}$ ) and rapid accessibility (mesopores; $2-50 \mathrm{~nm}$ ) at the same time..$^{10-12}$

Porous carbons are widely applied in energy storage devices, either as active materials in electric double layer capacitors, ${ }^{7-9}$ as anode materials for lithium ion storage, ${ }^{13}$ or as conductive

${ }^{a}$ TU Dresden, Department of Inorganic Chemistry, Bergstraße 66, D-01062 Dresden, Germany.E-mail: stefan.kaskel@chemie.tu-dresden.de

${ }^{b}$ School of Materials Science and Engineering, Georgia Institute of Technology, Atlanta, GA 30332, USA. E-mail: gleb.yushin@mse.gatech.edu

'Institute for Chemical and Bioengineering, ETH Zürich, Wolfgang-Pauli-Strasse 10, CH-8093 Zürich, Switzerland

${ }^{d}$ Center for Energy Convergence Research/Green City Technology Institute, Korea Institute of Science and Technology, PO Box 131, CheongRyang, Seoul 130-650, South Korea

${ }^{e}$ TU Dresden, Department of Physical Chemistry, Bergstrasse 66b, D-01062 Dresden, Germany

$\dagger$ Electronic supplementary information (ESI) available: Dynamic light scattering measurement and SEM data of PMMA template particles and QSDFT fitting comparison. See DOI: 10.1039/c4ta03327b

\$ These authors contributed equally.

$\S$ Current address: TU Dresden, Department of Inorganic Chemistry, Bergstraße 66, D-01062 Dresden, Germany. frameworks to contact active materials. ${ }^{14-17}$ Recently, these materials are frequently adopted in lithium-sulfur ( $\mathrm{Li}-\mathrm{S})$ battery cathodes because they can greatly improve the utilization of sulfur. Elemental sulfur is one of the most attractive active materials for Li battery technology because of its high theoretical gravimetric capacity of $1672 \mathrm{~mA} \mathrm{~h} \mathrm{~g}{ }^{-1}$, low cost, and its abundance in nature. ${ }^{\mathbf{1 4 , 1 8 - 2 0}}$ Porous carbons can mitigate polysulfide dissolution via physical adsorption and electrically connect nano-sized sulfur, which suffers from low intrinsic electric conductivity. The bimodal porous carbon materials having both micro- and mesopores may be advantageous because large mesopores can provide high pore volume for sulfur storage and allow for the rapid ion transport (and thus faster charge-discharge rates), while micropores induce reduced polysulfide dissolution and provide high surface area for sufficient electrical contact between sulfur and carbon. ${ }^{11,21}$

Carbide-derived carbons (CDCs) are synthesized by extraction of non-carbon species such as metals or semi-metals through physical (e.g. thermal decomposition) or chemical (e.g. high-temperature chlorine treatment) methods from carbide precursors. ${ }^{22-27}$ The main benefits of CDCs compared to activated carbons are the uniform and precisely controllable pore size and pore shape. ${ }^{28}$ Silicon removal from ordered mesoporous SiC produces CDCs that combine micropores with welldefined and ordered mesopores. ${ }^{29}$ Recently, different kinds of micro- mesoporous carbon ${ }^{30}$ and especially CDC materials ${ }^{11,31,32}$ were applied in Li-S battery cathodes with very promising results. While the micropores arise from the chlorination step, their mesopores are formed by hard- or soft-templating approaches using solid-state templates or amphiphilic 
structure-directing agents, respectively. The removal of the template requires an additional synthesis step in hard-templating routes (often accompanied by the use of extremely toxic substances such as hydrofluoric acid). Soft-templating approaches are accompanied by the use of large amounts of organic solvents and surfactants, which end up in an evaporated or a decomposed state. Sacrificial templating is an attractive alternative as no surfactant is required and the template removal does not require an additional synthesis step. The elimination of the pore forming templates takes place in parallel to the thermal conversion of the precursor. In this study, we report a unique route to synthesize micro- and mesoporous CDC materials by a sacrificial template method using poly(methylmethacrylate) (PMMA) spheres as a pore forming material. This novel class of CDC materials is a highly attractive host structure for the active material in $\mathrm{Li}-\mathrm{S}$ battery cathodes.

\section{Experimental}

\section{PMMA sacrificial template synthesis}

The polymethylmethacrylate (PMMA) template spheres were produced by a modified miniemulsion method. ${ }^{33} 6.2 \mathrm{~g}$ methylmethacrylate (Sigma Aldrich, 99\%) were mixed with $0.25 \mathrm{~g}$ hexadecane (Fluka) and $0.15 \mathrm{~g}$ of azo-bis-(isobutyronitril) (AIBN; Sigma Aldrich) as a polymerization catalyst. After the addition of the water phase consisting of $0.072 \mathrm{~g}$ sodium dodecyl sulfate (SDS, Fluka) in $24 \mathrm{~g}$ deionized water, the mixture was stirred for $10 \mathrm{~min}$ at room temperature (RT). The miniemulsion was prepared by ultrasonicating the emulsion for 2 min with Labsonic P (Sartorius) at $90 \%$ level ( 0.5 amplitude) under cooling in an ice bath. The mixture was then filtered over glass wool followed by polymerization at $80{ }^{\circ} \mathrm{C}$ for $24 \mathrm{~h}$ in a closed polyethylene bottle. Water was evaporated at $80{ }^{\circ} \mathrm{C}$ overnight in a Petri dish.

\section{CDC synthesis}

Micro- and mesoporous CDC materials were synthesized by intense mixing of $4.5 \mathrm{~g}$ of the PMMA spheres with $1.5 \mathrm{~g}$ allylhydridopolycarbosilane (SMP-10; Starfire Systems) in a mortar. The resulting bright yellow powder was then pyrolyzed in an alumina tube in a horizontal tubular furnace under flowing argon for $2 \mathrm{~h}$ at $800{ }^{\circ} \mathrm{C}$ (heating rate $30 \mathrm{~K} \mathrm{~h}^{-1}$ ). Chlorine treatment of the resulting mesoporous silicon carbide was performed in a quartz tube (inner diameter $25 \mathrm{~mm}$ ) in a horizontal tubular furnace. After argon purging $\left(150 \mathrm{ml} \mathrm{min}^{-1}\right)$ at room temperature (RT), the sample was heated to $800{ }^{\circ} \mathrm{C}$ (heating rate $\left.450 \mathrm{~K} \mathrm{~h}^{-1}\right)$ and the gas flow changed to a chlorine/argon $(80 \mathrm{ml}$ $\min ^{-1} / 70 \mathrm{ml} \mathrm{min}{ }^{-1}$ ) mixture for $3 \mathrm{~h}$. The CDC material was cooled down to $600{ }^{\circ} \mathrm{C}$ under argon flow $\left(150 \mathrm{ml} \mathrm{min}{ }^{-1}\right)$ followed by post-reductive treatment under hydrogen $(80 \mathrm{ml}$ $\min ^{-1}$ ) for $1 \mathrm{~h}$ for the removal of residual chlorine and chloride species. The CDCs were cooled to RT under argon flow.

\section{Structural characterization}

Dynamic light scattering experiments were carried out at RT with an aqueous dispersion of the PMMA particles in a plastic cuvette using a Zetasizer Nano-ZS (Malvern Instruments). The nitrogen adsorption/desorption isotherms were measured at -196 ${ }^{\circ} \mathrm{C}$ using an Autosorb 1C apparatus (Quantachrome Instruments). The specific surface area was calculated using the multi-point BET equation $\left(p / p_{0}=0.05-0.2\right)$. The total pore volume was determined at $p / p_{0}=0.99$. Pore size distributions were calculated using the quenched solid density functional theory (QSDFT) method (equilibrium model) for nitrogen on carbon with slit and cylindrically shaped pores. The CDC microstructure was characterized by using a Tecnai $\mathrm{G}^{2}$ F30 (FEI, Netherlands) operating at an accelerating voltage of $300 \mathrm{kV}$. Scanning electron microscopy (SEM) and electron dispersive X-ray spectroscopy (EDS) were performed using a Zeiss Ultra60 FE-SEM (Carl Zeiss, Germany) at a beam voltage of $5 \mathrm{kV}$ and a working distance of $4 \mathrm{~mm}$ for imaging and $8 \mathrm{~mm}$ for EDS. Thermogravimetric analysis (TGA) was performed under a nitrogen atmosphere at a heating rate of $5{ }^{\circ} \mathrm{C} \mathrm{min}{ }^{-1}$ using a TGA Q5000IR analyzer (TA instruments, USA). Raman spectroscopy was performed on a Renishaw RM-2000 Raman microscope using a $532 \mathrm{~nm}$ laser (Gem 532 from Laser Quantum) as the excitation source. XRD measurements were carried out on a STOE STADI P with $\mathrm{CuK} \alpha_{1}$ radiation $(\lambda=0.154 \mathrm{~nm})$.

\section{Electrode preparation and electrochemical characterization}

Sulfur-CDC composites were prepared as previously reported. ${ }^{\mathbf{1 1}}$ The S-CDC powders and polyacrylic acid (PAA) (Polysciences) as a binder were mixed in water-ethanol (1:3 by weight) to prepare a slurry for casting an electrode. The weight ratio of $\mathrm{S}-$ CDC to PAA binder was $85: 15$. No conductive additives were used. The slurry was stirred at room temperature for $1 \mathrm{~h}$ and cast on an aluminum foil. After drying overnight at room temperature under vacuum, coin cells were assembled with $1 \mathrm{M}$, $3 \mathrm{M}$, and $5 \mathrm{M}$ lithium bis(trifluoromethanesulfonyl)imide (LiTFSI) in dimethoxyethane (DME) : 1,3-dioxolane (DIOX) (1 : 1 by volume) as an electrolyte, a celgard2400 (Celgard) separator and a pure Li foil (Alfa Aesar, 99.9\%) anode. 0.2 $\mathrm{M} \mathrm{LiNO}_{3}$ (Alfa Aesar, 99.99\%) was added to the electrolyte as an additive. The cells were equilibrated for $24 \mathrm{~h}$ before operation. The average sulfur surface loading is $\sim 0.5 \mathrm{mg} \mathrm{cm}^{-2}$. The coin-cells assembled inside an Ar glovebox ( $<1 \mathrm{ppm}$ of $\mathrm{H}_{2} \mathrm{O}$, Innovative Technologies) were cycled between $3.0 \mathrm{~V}$ and $1.2 \mathrm{~V}$ vs. $\mathrm{Li} / \mathrm{Li}^{+}(\mathrm{V})$ in galvanostatic mode using an Arbin battery test system (Arbin Instruments). The cells were tested with different C-rates at $\mathrm{C} / 5$, $\mathrm{C} / 2, \mathrm{C}, 2 \mathrm{C}$ and $\mathrm{C} / 5$ to investigate the rate performance. The durability test was done at $\mathrm{C} / 5$ with separate cells. The coulombic efficiency was defined as $C_{\mathrm{Li}}$ extraction $/ C_{\mathrm{Li}}$ insertion.

\section{Results and discussion}

Carbide-derived carbons with a hierarchical pore structure are prepared by the infiltration of PMMA spheres with a polycarbosilane polymer precursor followed by simultaneous carbide formation/template removal and high-temperature chlorine treatment (Fig. 1a). The self-made PMMA spheres are obtained by a miniemulsion technique ${ }^{33}$ leading to a narrow size distribution (ESI, Fig. S1†) of the template particles and the 
(a)
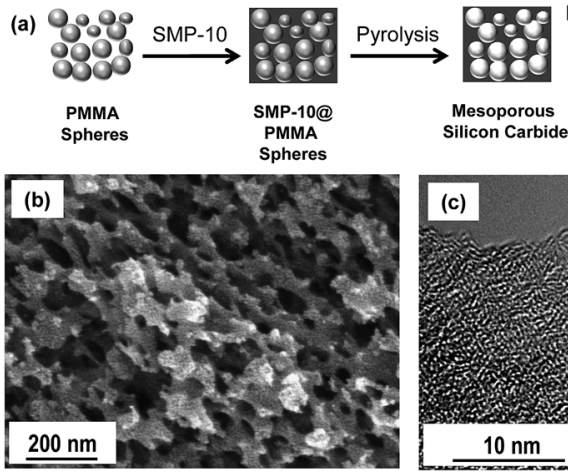
Mesoporous Silicon Carbide
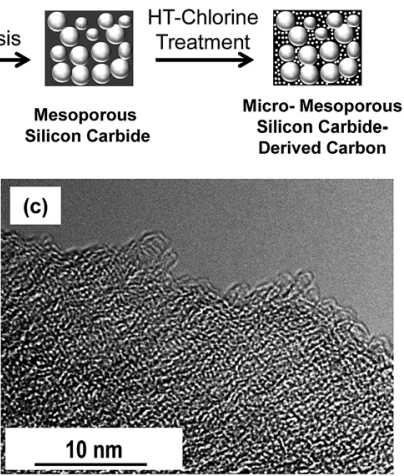

Fig. 1 Schematic of the synthesis procedure (a), SEM micrograph (b), and TEM micrograph (c) of hierarchical CDC from sacrificial PMMA templates.

CDC pores. SEM investigations of the template particles (Fig. $\mathrm{S} 1 \dagger$ ) and the CDC replica materials (Fig. 1b) show that the polymeric placeholders are of a near-spherical shape and that the single PMMA nanoparticles obtained after polymerization and drying are agglomerated and contain distinct contact areas which are important for advanced connectivity of the mesopores in the finally obtained carbon material. The diameter of the PMMA spheres determined by SEM $(40-80 \mathrm{~nm})$ is in good accordance with the size determined by dynamic light scattering $(90 \mathrm{~nm})$ experiments (Fig. S1 $\dagger$ ). The large pores in the CDC materials are comparable in size to the template particles indicating the precise control over the pore size provided by the sacrificial template route (Fig. 1b). TEM studies show the highly disordered microstructure of the templated CDC (Fig. 1c). It mainly consists of randomly oriented $\mathrm{sp}^{2}$ carbon fringes and no graphitic nanodomains can be observed as it is typical for polymer-based CDCs synthesized at comparable temperatures. ${ }^{31}$ In accordance, the Raman spectrum of the CDC material (Fig. S2 $\dagger$ ) shows the typical D band at $\sim 1350 \mathrm{~cm}^{-1}$, which is characteristic for a disordered carbon structure with a high degree of $\mathrm{sp}^{2}$ atoms, (i.e. disordered curved graphene sheets). The integrated intensity ratio $I_{\mathrm{D}} / I_{\mathrm{G}}$ of the $\mathrm{D}$ and $\mathrm{G}$ bands of 1.95 and the full width at half maximum (FWHM) of the D band of $150 \mathrm{~cm}^{-1}$ are comparable to other CDC structures prepared at comparable temperatures. ${ }^{31}$ It is well known that these carbon materials provide sufficient electric conductivity for their use as electrode materials due to their $\mathrm{sp}^{2}$-rich structure. ${ }^{31,34}$ As the graphene sheets are highly disordered at the same time and distinct graphitization does not take place, the typical graphite (002) peak appears only with moderate intensity in the X-ray diffraction (XRD) patterns of the CDCs (Fig. S3†).

The hierarchical character of the produced CDCs is proven by nitrogen physisorption measurements $\left(-196{ }^{\circ} \mathrm{C}\right)$ (Fig. 2a). The large specific surface area of $2434 \mathrm{~m}^{2} \mathrm{~g}^{-1}$ and the large micropore volume are responsible for the high uptake of nitrogen in the low-pressure area $\left(p / p_{0}<0.2\right)$. A distinct hysteresis loop can be observed at high relative pressure $\left(p / p_{0}=\right.$ 0.8-0.99) arising from the larger pores induced by the PMMAtemplate particles leading to a high total pore volume of $2.64 \mathrm{~cm}^{3} \mathrm{~g}^{-1}$. Furthermore, the absence of cavitation or pore
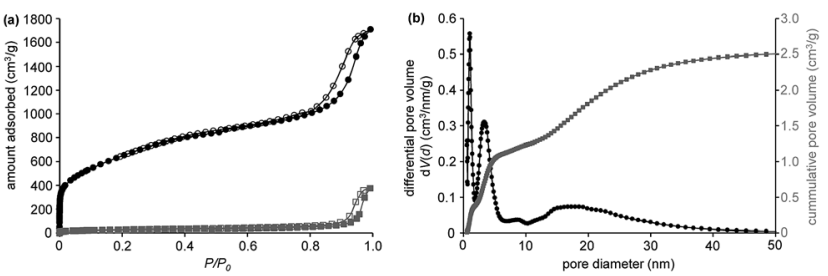

Fig. 2 Nitrogen adsorption/desorption (filled symbols/empty symbols) isotherms at $-196^{\circ} \mathrm{C}$ of hierarchical CDCs (black circles) and mesoporous silicon carbide precursors (grey squares) (a) and corresponding QSDFT pore size distribution of the CDC (b).

blocking effects indicates the high accessibility of the mesopores which is favorable for homogeneous infiltration of sulfur and enhanced electrolyte penetration. In accordance, the QSDFT pore size distribution shows the presence of large mesopores of 10-50 nm combined with micropores of $1.0 \mathrm{~nm}$ in size (Fig. 2b). Minor contributions of small mesopores $(3.3 \mathrm{~nm})$ are observed as previously reported for polymer-based carbidederived carbons. ${ }^{27}$ The good correlation between the experimental data and the used QSDFT method proves that this model calculates a reliable pore size distribution (Fig. S4†). As indicated by the hysteresis loop in the physisorption isotherm, the large mesopores are already present in the silicon carbide material obtained after PMMA decomposition, which shows a moderate specific surface area of $99 \mathrm{~m}^{2} \mathrm{~g}^{-1}$, while the micropores are inserted during the selective removal of silicon during high-temperature chlorine treatment (Fig. 2a). The silicon content of the finally obtained CDCs (determined by EDS) is below 0.1 atom\% indicating the high purity of the carbon materials. The comparably high oxygen content of $\sim 18$ atom $\%$ in the mesoporous silicon carbide precursors is likely originated from the oxygen containing groups of the sacrificial template particles. However, this effect does not negatively influence the purity of the finally obtained CDCs showing an oxygen content of only $\sim 0.5$ atom $\%$.

The CDCs obtained from PMMA templates simultaneously provide high micropore volume and high conductivity as it is typical for carbon materials with a $\mathrm{sp}^{2}$ dominated microstructure. Together with the high volume of precisely defined mesopores the facile synthesis scheme PMMA-templated CDCs are highly suitable materials for hosting the electrically insulating sulfur in Li-S battery cathodes.

Scanning electron microscopy (SEM) micrographs of the SCDC powder reveal almost no morphological changes after
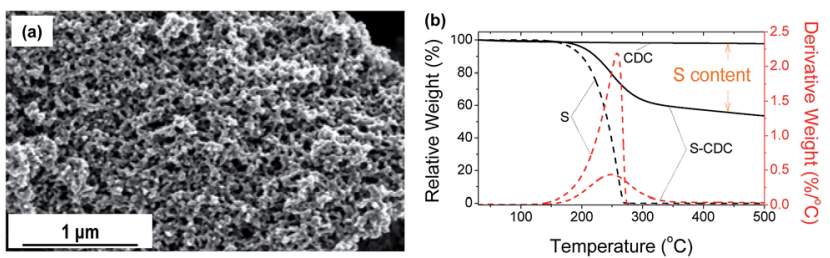

Fig. 3 SEM micrograph of $S$ infiltrated $C D C$ at high magnification (a) and TGA of pure CDC, pure $S$, and S-CDC composite (b). 
sulfur infiltration (Fig. 3a). No agglomerated or large sulfur residues on the particles' external surface are observed. Thermogravimetric analysis in a $\mathrm{N}_{2}$ atmosphere is used to investigate the thermal evaporation of sulfur, CDC, and S-CDC and the content of sulfur ( $\sim 45 \mathrm{wt} \%$ ) in the composite samples (Fig. 3b). The CDC material is stable over the investigated temperature range whereas both $\mathrm{S}-\mathrm{CDC}$ and pure sulfur begin to lose weight at $\sim 150{ }^{\circ} \mathrm{C}$. The evaporation of pure sulfur is completed at $\sim 280{ }^{\circ} \mathrm{C}$, but the active material in S-CDC preserves up to $\sim 350^{\circ} \mathrm{C}$. This phenomenon is beneficial as it indicates a strong physical bonding between sulfur and the CDC host. The sulfur entrapped in smaller pores evaporates at higher temperature compared to the sulfur in larger pores and furthermore thermal evaporation of sulfur is delayed in the presence of an adsorbent. ${ }^{21}$ The uniform distribution of sulfur inside the micro- and mesopores is confirmed by EDS mapping (Fig. S5 $\dagger$ ). A nitrogen physisorption measurement $\left(-196^{\circ} \mathrm{C}\right)$ of the S-CDC powder confirms (Fig. S6 ${ }^{\dagger}$ ) a confinement of sulfur in the carbon micropores. Compared to the pristine PMMA-templated CDC, the specific surface area is decreased to $586 \mathrm{~m}^{2} \mathrm{~g}^{-1}$. The micropore volume remaining after sulfur loading is only 0.068 $\mathrm{cm}^{3} \mathrm{~g}^{-1}$, revealing the preferred adsorption of the active material in the carbon micropores and large electrochemically active surface area. However, a relatively high mesoporosity is still available, as indicated by the remaining hysteresis loop at high relative pressure. The total pore volume of $1.09 \mathrm{~cm}^{3} \mathrm{~g}^{-1}$ serves for sufficient Li diffusion to the active material and can balance the volume expansion of up to $\sim 80 \%$ during the conversion of sulfur to $\mathrm{Li}_{2} \mathrm{~S}$.

The S-CDC cathodes exhibit relatively stable cycling performance and high capacity utilization at $\mathrm{C} / 5$ in various electrolytes (Fig. 4a). After an initial discharge capacity of $1209 \mathrm{~mA} \mathrm{~h} \mathrm{~g}_{\mathrm{s}}{ }^{-1}$, the capacity of S-CDC in 1 M LiTFSI maintains $44 \%$ of this value after 50 cycles. The $\mathrm{S}-\mathrm{CDC}$ cathodes in $3 \mathrm{M}$ and $5 \mathrm{M}$ electrolytes show comparable initial discharge capacities $\left(1324 \mathrm{~mA} \mathrm{~h} \mathrm{~g}_{\mathrm{s}}{ }^{-1}\right.$ for the cell in the $3 \mathrm{M}$ electrolyte and $1404 \mathrm{~mA} \mathrm{~h} \mathrm{~g}_{\mathrm{s}}{ }^{-1}$ for the cell in the
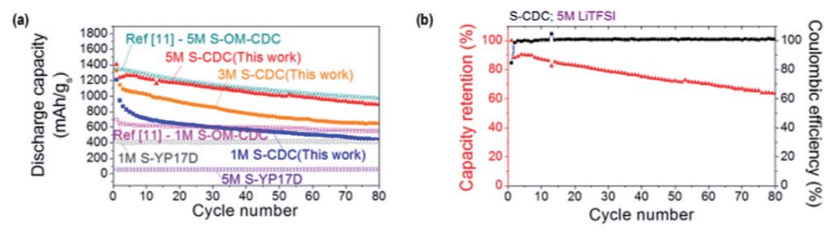

(c)

(d)
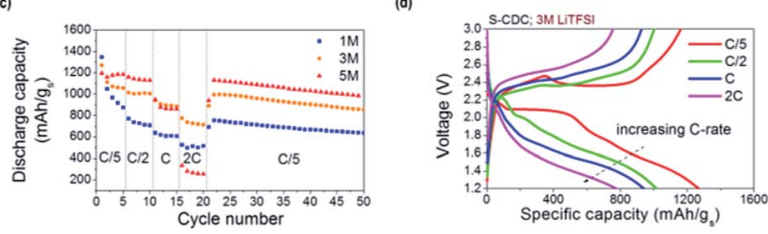

Fig. 4 Discharge capacity of S-CDC cathodes and sulfur infiltrated commercial activated carbon (S-YP17D) composite cathodes in electrolytes with different LiTFSI concentrations over 80 cycles at C/5 (a), capacity retention and coulombic efficiency (CLi extraction/CLi insertion) of S-CDC in the $5 \mathrm{M}$ electrolyte at C/5 current density (b), discharge capacity of S-CDC at different C-rates from C/5 to $2 C$ (c), and voltage profile of S-CDC in the $3 \mathrm{M}$ electrolyte at different $\mathrm{C}$-rates (d). The capacities are normalized by the weight of sulfur.
5 M electrolyte) but exhibit a largely improved capacity retention of $55 \%$ and $72 \%$ at the end of 50 cycles. Especially the initial capacity decay of S-CDC in $1 \mathrm{M}, 3 \mathrm{M}$, and $5 \mathrm{M}$ electrolytes within the first ten cycles is $42 \%, 23 \%$, and $13 \%$ respectively. This clearly indicates that the polysulfide dissolution into the electrolyte is refrained due to the common ion effect and the lower amount of available free solvent molecules. ${ }^{11,35,36}$ In consequence, the unfavorable polysulfide shuttle mechanism is reduced. SEM studies of the cycled cathodes reveal very different morphologies. A significant amount of dissolved high order polysulfides precipitated on the surface of the CDC particles in the case of $1 \mathrm{M}$ electrolyte. Therefore, many of the pores become blocked by insoluble low order polysulfides (Fig. S7a†). In contrast, in the 5 $\mathrm{M}$ electrolyte (Fig. S7b $\dagger$ ), the morphology of CDC is almost identical to its original state (Fig. 3), indicating that the polysulfide dissolution is effectively suppressed. Moreover, EDS analysis on cycled cathodes clearly corroborates improved sulfur retention in the S-CDC composite by a high molarity electrolyte (Fig. S7c $\dagger$ ).

It should be noted that the structure and pore properties of carbon may play crucial roles especially in high molarity (and thus more viscous) electrolytes, as previously shown. Both low specific surface area graphite and high surface area but exclusively microporous activated carbon demonstrate noticeably reduced sulfur utilization in a high molarity electrolyte mainly due to the increased ionic resistance and incomplete electrolyte accessibility. ${ }^{11,37}$ We compare the novel CDC material prepared by the sacrificial template method as a sulfur hosting material with other porous carbon structures; commercially available and strictly microporous activated carbon (YP17D) powders ${ }^{\mathbf{1 2}}$ and hierarchical micro- and ordered mesoporous silicon carbide-derived carbon chlorinated at $900{ }^{\circ} \mathrm{C}$ (OM-CDC900). ${ }^{11}$ Microporous carbon shows very stable cycling performance because the dissolution of polysulfides is suppressed in small micropores. However, random, small, and bottle-neck pore structures present in activated carbons derived from natural sources (e.g. coconut) can be easily clogged with electrically insulating and insoluble low order polysulfides. Hence, a limited amount of sulfur can be electrochemically utilized. Within this electrode, increasing electrolyte molarity to $5 \mathrm{M}$ significantly increases bulk ionic resistance and most of sulfur becomes inaccessible for $\mathrm{Li}$ ions (Fig. 4a). In contrast, in the produced mesoporous CDC, high capacity utilization and overall improved performance are observed at higher molarities. This behavior was also observed in our previous study with hierarchical ordered bimodal S-OM-CDC900 cathodes. The comparison of S-CDC (sacrificial method) with S-YP17D and S-OM-CDC900 samples (Fig. 4a) clearly reveals the importance of pore properties of the $\mathrm{S}$ hosting carbon structure. Especially dual pore sizes are necessary in a high molarity electrolyte as the small micropores are beneficial for polysulfide retention and larger mesopores provide sufficient Li ion access. This optimized structure of small micropores and larger mesopores is strongly required for stable and high capacity Li-S cells.

While polysulfide dissolution is highly suppressed in the $5 \mathrm{M}$ electrolyte, the capacity keeps decreasing with cycling (Fig. 4b). This capacity reduction can be explained by the previously 
reported highly resistive low order polysulfide precipitation on the lithium metal. ${ }^{11}$ The cycled lithium metal anodes in both $1 \mathrm{M}$ and $5 \mathrm{M}$ electrolytes exhibit a rough surface likely due to polysulfide precipitation as well as lithium deposition (Fig. S8a and $\mathrm{S} 8 \mathrm{~b} \dagger$ ). Especially the sulfur content originated from polysulfides (all the samples were washed with an excessive amount of DIOX solvent to remove remaining salt) is much higher in the case of the $5 \mathrm{M}$ electrolyte (Fig. S8c $\dagger$ ) explaining the origin of slow capacity decrease in a high molarity electrolyte. Interestingly, we notice that the coulombic efficiency nonetheless reaches almost $100 \%$, indicating that polysulfide dissolution is greatly reduced except for the initial cycles.

Cycling of the S-CDC cathodes at various C-rates evaluates their rate capabilities as well as their stability upon cycling (Fig. 4c). The first discharge capacity of S-CDC in the $1 \mathrm{M}$ electrolyte is $1347 \mathrm{~mA} \mathrm{~h} \mathrm{~g}_{\mathrm{s}}{ }^{-1}$ at $\mathrm{C} / 5$ and the discharge capacity after 5 cycles at $\mathrm{C} / 5$ decreases by $35 \%$ to $875 \mathrm{~mA} \mathrm{~h} \mathrm{~g}_{\mathrm{s}}{ }^{-1}$. After this early capacity decay, which is likely due to the polysulfide dissolution, the discharge capacity stabilizes at $\sim 730$ $\mathrm{mA} \mathrm{h} \mathrm{g}_{\mathrm{s}}{ }^{-1}, \sim 615 \mathrm{~mA} \mathrm{~h} \mathrm{~g}_{\mathrm{s}}{ }^{-1}$, and $\sim 510 \mathrm{~mA} \mathrm{~h} \mathrm{~g}_{\mathrm{s}}{ }^{-1}$ for $\mathrm{C} / 2, \mathrm{C}$, and $2 \mathrm{C}$, respectively. The cells in the $3 \mathrm{M}$ electrolyte demonstrate reduced capacity decay during the initial five $\mathrm{C} / 5$ cycles and also show similar rate capabilities compared to the cells with the $1 \mathrm{M}$ electrolyte. In contrast, the S-CDC cathode in the $5 \mathrm{M}$ electrolyte exhibits a very stable initial capacity of $1196 \mathrm{~mA} \mathrm{~h} \mathrm{~g}_{\mathrm{s}}{ }^{-1}$ and a very small capacity decay of $\sim 5 \%$ when the C-rate changes from $\mathrm{C} / 5$ to $\mathrm{C} / 2$. A further increase of the C-rate to $\mathrm{C}$ and $2 \mathrm{C}$ abruptly decreases sulfur utilization likely due to the high over potential (viscous nature of the $5 \mathrm{M}$ electrolyte). However, when the C-rate is switched from $2 \mathrm{C}$ to $\mathrm{C} / 5$ again, the original capacity was mostly recovered demonstrating good rate performance and stability of the cathode material. This good rate capability with a high molarity electrolyte could be achieved due to the unique structure of the CDC material reported in this study. The electrolyte has easy access to sulfur through the large mesopores and the electron transport is improved by the conductive cellular structure. The voltage profiles of the S-CDC electrodes in the $3 \mathrm{M}$ electrolyte at different C-rates show moderate polarization with an increasing C-rate from $\mathrm{C} / 5, \mathrm{C} / 2, \mathrm{C}$, to $2 \mathrm{C}$ indicating high-rate capability (Fig. 4d). In other types of CDC (not reported in this paper) as well as in activated carbons, carbon nanotubes and carbon onions we observed only a very small capacity $\left(<10 \mathrm{~mA} \mathrm{~h} \mathrm{~g}{ }^{-1}\right.$-CDC) in a similar voltage range, which may suggest that the ion sorption contribution to the capacitance is likely to be very small. ${ }^{38}$ The greatly improved capacity in this study originates mainly from the high molarity electrolyte and the dual pore size distribution of CDC.

Both S-CDC cells in $1 \mathrm{M}$ and $3 \mathrm{M}$ electrolytes show the typical voltage profile of the lithium sulfur battery but cathodes in the 5 M electrolyte show a long second plateau at lower voltage due to high flow resistance of the electrolyte (Fig. 5). ${ }^{\mathbf{1 1}}$ Upon cycling, polarization and capacity decay are less distinct at higher salt concentrations in the electrolyte. Higher molarity is also favorable because the initial charging barrier decreases with increasing salt concentration. It was reported that this barrier originated from the nucleation of a new phase (dissolved
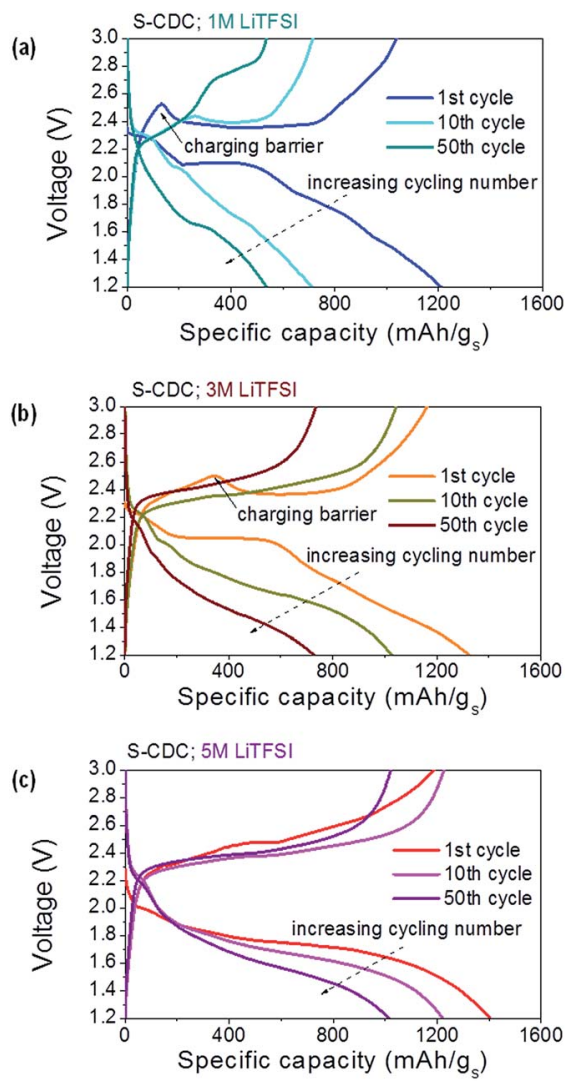

Fig. 5 Voltage profiles of S-CDC in different electrolytes at C/5; $1 \mathrm{M}$ electrolyte (a), $3 \mathrm{M}$ electrolyte (b), and $5 \mathrm{M}$ electrolyte (c). The capacity is normalized by the weight of sulfur.

polysulfide).${ }^{39}$ We believe that this barrier could be suppressed with increasing electrolyte molarity since polysulfide dissolution is greatly refrained. Hence the number of nucleation sites is decreased.

\section{Conclusions}

We have synthesized novel nanostructured CDC and S-CDC composites and exploited their feasibility of usage as lithiumsulfur battery cathodes. The micro- and mesoporous CDCs, produced using spherical PMMA particles as a sacrificial template, reveal uniform pore size and pore shape with a specific surface area of $2434 \mathrm{~m}^{2} \mathrm{~g}^{-1}$ and a total pore volume as high as $2.64 \mathrm{~cm}^{3} \mathrm{~g}^{-1}$. CDCs are characterized by high purity, which is beneficial for the electrochemical reactions and EDS mapping shows uniform $\mathrm{S}$ distribution throughout the carbon framework in the S-CDC composite. The novel CDC, due to its bimodal porosity, allows the utilization of high molarity electrolytes in S-CDC and therefore S-CDC/Li cells exhibit good rate performance and stability. S-CDC cathodes in the $5 \mathrm{M}$ electrolyte show the highest discharge capacities and capacity retention. The unique network structure of the carbon host material enables sulfur to be well distributed through the conductive media and at the same time to be easily accessible for the electrolyte. 


\section{Acknowledgements}

M.O., W.N., and S.K. gratefully acknowledge financial support by DFG and the project "Nanomaterials for future generation Lithium Sulfur batteries" ("MaLiSu"). M.O. also acknowledges the German academic exchange service (DAAD) for financial support. Different aspects of this work were supported by the Energy Efficiency \& Resources program of the Korea Institute of Energy Technology Evaluation and Planning (KETEP) funded by the Korea government Ministry of Knowledge Economy (grant 20118510010030) and by the US Army Research Office (grant W911NF-12-1-0259). The TEM used in this work is supported by National Science Foundation (NSF) funding (DMR 0922776).

\section{Notes and references}

1 M. Oschatz, L. Borchardt, I. Senkovska, N. Klein, M. Leistner and S. Kaskel, Carbon, 2013, 56, 139.

2 M. Sevilla, R. Foulston and R. Mokaya, Energy Environ. Sci., 2010, 3, 223.

3 A. Silvestre-Albero, S. Rico-Francés, F. Rodriguez-Reinoso, A. M. Kern, M. Klumpp, B. J. M. Etzold and J. SilvestreAlbero, Carbon, 2013, 59, 221.

4 L. Borchardt, F. Hasche, M. R. Lohe, M. Oschatz, F. Schmidt, E. Kockrick, C. Ziegler, T. Lescouet, A. Bachmatiuk, B. Buechner, D. Farrusseng, P. Strasser and S. Kaskel, Carbon, 2012, 50, 1861.

5 L. R. Radovic and F. Rodriguez-Reinoso, Chem. Phys. Carbon, 1997, 25, 243.

6 S. Porada, L. Borchardt, M. Oschatz, M. Bryjak, J. S. Atchison, K. J. Keesman, S. Kaskel, P. M. Biesheuvel and V. Presser, Energy Environ. Sci., 2013, 6, 3700.

7 P. Simon and Y. Gogotsi, Nat. Mater., 2008, 7, 845.

8 L. Borchardt, M. Oschatz and S. Kaskel, Mater. Horiz., 2014, 1, 157.

9 F. Béguin, V. Presser, A. Balducci and E. Frackowiak, Adv. Mater., 2014, 26, 2219.

10 M. Oschatz, L. Borchardt, S. Rico-Francés, F. RodríguezReinoso, S. Kaskel and J. Silvestre-Albero, Langmuir, 2013, 29, 8133.

11 J. T. Lee, Y. Zhao, S. Thieme, H. Kim, M. Oschatz, L. Borchardt, W. Cho, S. Kaskel and G. Yushin, Adv. Mater., 2013, 25, 4573.

12 J. T. Lee, Y. Zhao, H. Kim, W. I. Cho and G. Yushin, J. Power Sources, 2014, 248, 752.

13 Y. S. Hu, P. Adelhelm, B. M. Smarsly, S. Hore, M. Antonietti and J. Maier, Adv. Funct. Mater., 2007, 17, 1873.

14 X. Ji, K. Lee and L. F. Nazar, Nat. Mater., 2009, 8, 500.

15 L. Wang, X. He, J. Li, W. Sun, J. Gao, J. Guo and C. Jiang, Angew. Chem., Int. Ed., 2012, 51, 9034.

16 J. Fan, T. Wang, C. Yu, B. Tu, Z. Jiang and D. Zhao, Adv. Mater., 2004, 16, 1432.

17 J. Lee, M. C. Orilall, S. C. Warren, M. Kamperman, F. J. DiSalvo and U. Wiesner, Nat. Mater., 2008, 7, 222.
18 R. Elazari, G. Salitra, A. Garsuch, A. Panchenko and D. Aurbach, Adv. Mater., 2011, 23, 5641.

19 X. Ji, S. Evers, R. Black and L. F. Nazar, Nat. Commun., 2011, 2, 1293/1.

20 E. Peled, A. Gorenshtein, M. Segal and Y. Sternberg, J. Power Sources, 1989, 26, 269.

21 C. Liang, N. J. Dudney and J. Y. Howe, Chem. Mater., 2009, 21, 4724.

22 G. Yushin, R. Dash, J. Jagiello, J. E. Fischer and Y. Gogotsi, Adv. Funct. Mater., 2006, 16, 2288.

23 G. Yushin, Y. Gogotsi and A. Nikitin, Carbide-Derived Carbon, in Nanomaterials Handbook, ed. Y. Gogotsi, FL CRC Press, Boca Raton, 2006.

24 E. N. Hoffman, G. Yushin, T. El-Raghy, Y. Gogotsi and M. W. Barsoum, Microporous Mesoporous Mater., 2008, 112, 526.

25 S. Urbonaite, J. M. Juarez-Galan, J. Leis, F. RodriguezReinoso and G. Svensson, Microporous Mesoporous Mater., 2008, 113, 14.

26 V. Presser, M. Heon and Y. Gogotsi, Adv. Funct. Mater., 2011, 21, 810.

27 M. Oschatz, L. Borchardt, M. Thommes, K. A. Cychosz, I. Senkovska, N. Klein, R. Frind, M. Leistner, V. Presser, Y. Gogotsi and S. Kaskel, Angew. Chem., Int. Ed., 2012, 51, 7577.

28 Y. Gogotsi, R. K. Dash, G. Yushin, T. Yildirim, G. Laudisio and J. E. Fischer, J. Am. Chem. Soc., 2005, 127, 16006.

29 M. Oschatz, E. Kockrick, M. Rose, L. Borchardt, N. Klein, I. Senkovska, T. Freudenberg, Y. Korenblit, G. Yushin and S. Kaskel, Carbon, 2010, 48, 3987.

30 M. Oschatz, S. Thieme, L. Borchardt, M. R. Lohe, T. Biemelt, J. Brueckner, H. Althues and S. Kaskel, Chem. Commun., 2013, 49, 5832.

31 M. Oschatz, L. Borchardt, K. Pinkert, S. Thieme, M. R. Lohe, C. Hoffmann, M. Benusch, F. M. Wisser, C. Ziegler, L. Giebeler, M. H. Rümmeli, J. Eckert, A. Eychmüller and S. Kaskel, Adv. Energy Mater., 2014, 4, 1300645/1.

32 S. Thieme, J. Brueckner, I. Bauer, M. Oschatz, L. Borchardt, H. Althues and S. Kaskel, J. Mater. Chem. A, 2013, 1, 9225.

33 K. Landfester, N. Bechthold, F. Tiarks and M. Antonietti, Macromolecules, 1999, 32, 5222.

34 K. Faber, F. Badaczewski, M. Oschatz, G. Mondin, W. Nickel, S. Kaskel and B. M. Smarsly, J. Phys. Chem. C, 2014, 118, 15705.

35 E. S. Shin, K. Kim, S. H. Oh and W. I. Cho, Chem. Commun., 2013, 49, 2004.

36 L. Suo, Y. S. Hu, H. Li, M. Armand and L. Chen, Nat. Commun., 2013, 4, 1481.

37 Y. Mikhaylik and J. R. Akridge, J. Electrochem. Soc., 2004, 151, A1969.

38 W. Gu, N. Peters and G. Yushin, Carbon, 2013, 53, 292.

39 Y. Yang, G. Zheng, S. Misra, J. Nelson, M. F. Toney and Y. Cui, J. Am. Chem. Soc., 2012, 134, 15387. 